\title{
Effective Solid Waste Management Practices in Developing Countries: Problems and Prospects
}

\author{
Audu, H.A.P Iyeke, S.D Aladenika, A \\ Department of Civil Engineering, Faculty of Engineering, University of Benin, P.M.B 1154, Benin City, Edo \\ State, Nigeria
}

\begin{abstract}
Solid waste generation increases with population expansion and economic development. Uncontrolled dumping and improper waste handling cause a variety of problems, including contaminating water, attracting insects and rodents, and increasing flooding due to blocked drainage canals or gullies. In addition, it may result in safety hazards from fires or explosions and increased greenhouse gas (GHG) emissions, which contribute to climate change. The target of this study is to review some of the fundamental issues associated with solid waste generation, storage, collection, transshipment, treatment and disposal and proposed likely suggestions that can help alleviate them
\end{abstract}

Keywords: Sanitary landfill, climate change, waste generation, storage, collection, transshipment and treatment. DOI: $10.7176 /$ JNSR/10-2-01

Publication date: January $31^{\text {st }} 2020$

\section{Introduction}

Management of solid waste reduces or eliminates adverse impacts on the environment and human health and supports economic development and improved quality of life. A number of processes are involved in effectively managing waste for a municipality. These include monitoring, collection, transport, processing, recycling and disposal (Tchobanoglous et al., 1993). The basic concept behind waste management is the waste hierarchy, where the most effective approaches to managing waste are at the top. Waste management is in contrast to waste minimization. Waste management focuses on processing waste after it is created, concentrating on re-use, recycling, and waste-to-energy conversion rather than eliminating the creation of waste in the initial phases of production (Davidson, 2011). Waste minimization is a process that involves reducing the amount of waste produced in society and helps eliminate the generation of harmful and persistent wastes, supporting the efforts to promote a more sustainable society (USEPA, 2012). Waste minimization involves redesigning products and/or changing societal patterns, concerning consumption and production, of waste generation, to prevent the creation of waste (Davidson, 2011). Waste minimization involves efforts to minimize resource and energy use during manufacture. For the same commercial output, usually the fewer materials are used, the less waste is produced. Waste minimization usually requires knowledge of the production process, cradle-to-grave analysis (the tracking of materials from their extraction to their return to earth) and detailed knowledge of the composition of the waste.

The most environmentally resourceful, economically efficient, and cost-effective way to manage waste is to know how to address the problem in the first place. Waste minimization should be seen as a primary focus for most waste management strategies. Proper waste management can require a significant amount of time and resources; therefore, it is important to understand the benefits of waste minimization and how it can be implemented in all sectors of the economy, in an effective, safe and sustainable manner (Davidson, 2011). The three R's are commonly used terms in waste management; they stand for "reduce, reuse, and recycle". As waste generation rates have risen, processing costs increased, and available landfill space decreased, the three R's have become a central tenet in sustainable waste management efforts (El-Haggar, 2007; Seadon, 2006; Suttibak and Nitivattananon, 2008; Tudor et al., 2011). The concept of waste reduction, or waste minimization, involves redesigning products or changing societal patterns of consumption. The most effective way to reduce waste is by not creating it in the first place, and so reduction is placed at the top of waste hierarchies (USEPA, 2010). In many instances, reduction can be achieved through the reuse of products. Efforts to take action to reduce waste before waste is actually produced can also be termed pre-cycling (HRM, 2010). Reusing products displaces the need to buy other products thus preventing the generation of waste (USEPA, 1995; Davis, 2008). Minimizing waste through reduction and reuse offers several advantages including: saving the use of natural resources to form new products and the wastes produced in the manufacturing processes; reducing waste generated from product disposal; and reducing costs associated with waste disposal (USEPA, 2010). It is inevitable that waste will be created as a by-product of daily human living (Kim, 2002), but in many cases it is possible for this waste to be diverted and recycled into valuable new materials. Glass, plastic and paper products are commonly collected and reformed into new materials and products. Recycling products offer many of the benefits of waste reduction efforts (displacing new material usage, reducing waste generated and the costs associated with disposal) but recycling requires energy and the input of some new materials, thus placing it lower on the waste hierarchy than reduction and reuse (Davis, 2008; USEPA, 2010) 


\section{Research Methodology}

\subsection{Description of Study Area}

The study area is Warri in Delta state. Warri is one of the most important towns in Delta state, located in the SouthSouth geo-political zone of Niger Delta Region of Nigeria. Warri is located within latitudes $5^{0} 28^{\prime} 10.79^{\prime \prime} \mathrm{N}$ to $5^{0}$ $37^{\prime} 27.99^{\prime \prime} \mathrm{N}$ and longitudes $5^{0} 40^{\prime} 32.78^{\prime \prime} \mathrm{E}$ to $5^{0} 51^{\prime} 51.47^{\prime \prime} \mathrm{E}$ which is $399.809 \mathrm{~km}^{2}$ by area. It is situated $48 \mathrm{~km}$ upstream from the port of Forcados and at the terminus of road from Sapele and Ughelli. It has a navigable channel of water front of about 61meters. As a major industrial city in Delta state, on the Niger-Delta region bounded by Warri North LGA in the northern part of the state, in the west by Warri southwest LGA, in the east by Sapele LGA while in the south by Burutu LGA. There are creeks in the area such as Tori creek, Warri creek, and the major river. Warri is characterized by two major seasons namely, the rainy (wet) season and the dry season. The rainy season lasts from April to October which is a period of seven months. There is however a break in the rainy season by August after which it resumes and the rainfall becomes stronger. The dry season (harmattan) is short and starts from November to March. The effect of the short period of harmattan is minor and heavy down pour seldom occurs in the heart of the dry season. Warri experiences high annual rainfall of over $3,000 \mathrm{~mm}$, which is distributed throughout the year. The temperature is uniformly high with an annual means of $30^{\circ} \mathrm{C}$ and very low daily range of $28^{\circ} \mathrm{C}$ with relative humidity as high as $85 \%$. The population of Warri has increased over the years. Warri metropolis is one of the rapidly growing cities in Nigeria with a population rising rapidly from 55,256 in 1963, 280,561 in 1980, and 511,074 in 1991 to 632,243 in 2006 and estimated to be 930,000 in 2016 (Tajuddin, 2003). The satellite imagery of Warri, Delta State is shown in Figure 1

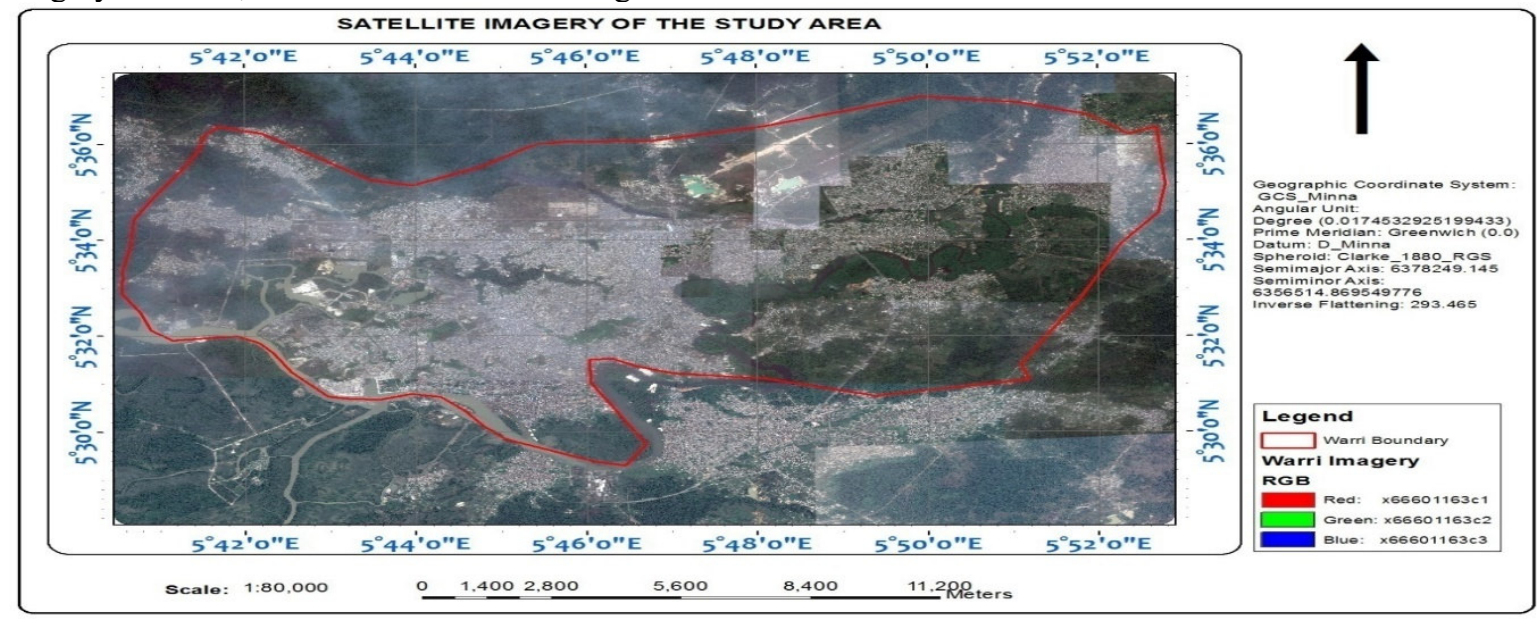

Figure 1: Satellite imagery of Warri, Delta State (Adopted from Google Earth)

\section{Issues of solid waste management within the study area}

Basically, waste management scheme consist of the following basic elements:
i. Waste Generation
ii. Waste Storage
iii. Waste Collection
iv. Waste Transhipment /Transfer Station
v. Waste Treatment
vi. Waste Disposal

\subsection{Waste Generation}

This refers to the sources of the waste or its origin. They include (Rao, 2004):

i. Residential / Domestic Watse: This includes food waste, cloths, beddings, papers, plastics, ceramics, metals, wood

ii. Commercial Waste:Waste generated as a result of commercial activities. This includes paper, garbage, plastics, clothings, ceramics, metals

iii. Institutional Waste: Waste generated from institution, learning centres and other government centres such as paper, plastics cardboard, wood.

iv. Agricultural Waste:Waste such as Poultry/Animal droppings, decomposed plants and animals (inorganic manure), and garbage.

v. Special Waste: These are bulky wastes such as street sweepings, dead animals and abandonned vehicles (Sincero et al., 2006).

vi. Industrial Waste: Industrial wastes differ depending on the type of industries. Typical examples of wastes 
and the industries generating them are as follows; Polymer Industry (plastics, rubber, e.t.c), Nuclear Industry (Radioactive Waste), Paper Industry (Papers), Glass Blowing Indusrty (Glass), Furniture Industry (Wood), Metallurgy Industry (Metals).

\subsubsection{Issues relating to Waste Generation}

1. Knowing the amount of solid waste generated

2. The issue of "Source Reduction"

One basic problem that has militated against most solid waste management schemes is the under estimation of the amount of solid waste generated. This has led to poor design calculation which has propagated into incorrect capacity of waste management systems. This issue can best be addressed by;

i. Having to do a correct population estimation so as to be able to identify the actual number of people generating the waste

ii. Identify the basic factors affecting the nature of solid waste generated such as: Emergency Situation, Social Activities, Nature of Industries, Seasons of the year and its effects, Life Style of the people, etc.

iii. A combination of these two factors will help to give a more accurate estimate of the amount of solid waste generated, therafter, the Excess Capacity Principle which acts like the safety factor during the actual design of the waste management scheme must be applied during the design and construction of the waste disposal systems.

iv. More also, efforts must be made to reduce the quantity of waste generated. For the solid waste manager, source reduction is an unfamiliar activity as it has not been included in previous waste management systems. From a community perspective, source reduction is the most desired activity because the community does not have to incur cost for (waste handling, waste recycling and waste disposal) for waste that is never created and never delivered to the waste management scheme.

The positive impact of source reduction include among others:

i. $\quad$ Fewer materials will become part of the disposable waste of a community.

ii. Source reduction is an alternative that will conserve resources and also has a lot of economic viability.

iii. Source reduction will reduce the charge on wastehandling, waste disposal and waste recycling since no cost is incurred on waste that is never generated (Rao, 2004).

iv. It will allow for effecient waste storage and collections.

v. It will reduce the problems associated with waste sorting.

The principal issue with source reduction for waste management agencies is to find ways and means to reduce the amount of waste generated at source. The most practical and promising methods appear to be:

i. Enact laws to minimize the use of virgin materials

ii. Adopting variable rate charges

iii. Setting standards for product manufacturing and packaging

iv. Consume more and throw - away less

v. $\quad$ Purchase durable, long lasting goods and products

vi. Avoid buying goods which we do not have need for

vii. Mend cloths instead of throwing them away

viii. Choose furniture and luggage that will stand up to vigorous use

\subsection{Waste Storage}

After generation, the waste needs to be properly stored. The way we store our waste determines how effective the collection will be. Wastes are normally stored in bins (small, big and medium bins) (Davison, 2011).

\subsubsection{Issues Relating to Waste Storage}

i. Availability of waste storage facilities.

ii. Effective utilization of the storage facilities if available

iii. Attitude of the people towards ensuring effective storage

iv. Wrong location of storage facilities

v. Inadequate sizes of available storage facilities

In most cases, the waste storage facilities are not available, in cases where they are available, individuals do not even use them, they end up throwing the waste near the bins either due to the fact that the bin is filled up or the person carrying the waste is too small to take advantage of the height of bin, more also, bad attitude of so many persons as they prefer to throw away the waste indiscriminately rather than dispose them properly. Addressing this issue will require (Egunjobi, 1983):

i. Provision of storage bins of adequate capacity

ii. Appriopriate training and public orientation on proper storage of the solid waste

iii. Lectures and orientation on the hazards of indiscriminate disposal of solid waste.

iv. Personal discipline on the attitude of people towards waste handling 


\subsection{Waste Collection}

In organized waste management systems, one needs to effectively define where the storage bin should be placed to allow for easy collection. Depending on the mode of storage, collection may be easy or nasty. If wastes are not properly stored, problems can result during the collection stage ranging from: accidents from broken bottles to epidermics and diseases and odour which might make life highly uncomfortable for the people living around the collection routes.

\subsubsection{Issues relating to Waste Collection}

Some of the major problems associated with the collection systems include:

i. Equipment problems

ii. Workers well-being problems

iii. Transportation problems

iv. Personnel problems

v. Management problems

vi. Route problems

vii. $\quad$ Location of Bins

viii. $\quad$ Sizes of Bins

The way forward includes:

i. Provision of basic equipment such as storage bins, head pans, shovels, boots, handgloves, mouth and nose masks and other minor equipments that will aid effective collection of the waste.

ii. Collection must be treated as a transportation problem, hence transportation vehicles must be provided, arrangements must be made for fueling and the vehicles must possess mechanical arrangement for compaction and off loading. Provision must also be made for coverage of the waste to avoid waste dispersion.

iii. The well-being of the workers must be placed as top priority, they must be well motivated, well paid and respected and they must be given every thing they need to allow them function properly.

iv. The numbers of personnel must be such that will be able to take care of particular locations and areas if not enough, then more should be employed and properly trained on the job.

v. The collection route must be properly designed to allow for effective collection of the solid waste. Some of the factors that must be considered before planning and designing waste collection routes are as follows: Location of refuse bin, Volume of waste at each point, Travel time, Assessibility and Location of transfer station (Egunjobi, 1983).

\subsection{Transhipment / Transfer Stations}

This refers to the bulk movement of the solid waste from the collection point to another loaction called the transfer station before the final disposal point. The advantages of the transfer station are as follows:

i. $\quad$ Reduce the cost of transporting the waste directly to the point of disposal

ii. It allows for the proper sorting of the waste

iii. Allows for abundant biogas generation

Some of the hazards of transfer station are:

i. Difficulty in sorting the waste

ii. Obnoxious smell

iii. Disease outbreak expecially when it is close to residential buildings

\subsubsection{Issues relating to Waste Transshipment}

The number of transfer stations needed for effective waste management scheme is guided by the following factors:

i. Waste generation rate: based on the economic status of the people, social activities, emergency situation, life style and presence of industries and institutions

ii. The types and composition of the waste.

iii. Population and its spread.

To determine the optimum number of transfer stations, the application of systems approach has been considered the best method since as the numbers of transfer stations increases, the transportation cost reduces while the cost of building and maintenance increases, data are thus generated based on this relationship and a graphical plot of total cost versus number of transfer station is obtained. The minimum point of the total cost graph is then projected downward to determine the optimum number of transfer station needed for an effective waste management system.

\subsubsection{Factors against One Very Large Transfer Station}
i. Overall transportation cost will increase
ii. Sorting will be very difficult since all the wastes are dumped in one place
iii. Requires large land space
iv. Odour and health risks
v. Epidemics and spread of deadly diseases 


\subsection{Waste Treatment}

Waste treatment techniques seek to transform the waste into a form that is more manageable, reduce the volume or reduce the toxicity of the waste thus making the waste easier to dispose of. Treatment methods are selected based on the composition, quantity, and form of the waste material. The treatment methods are as follows

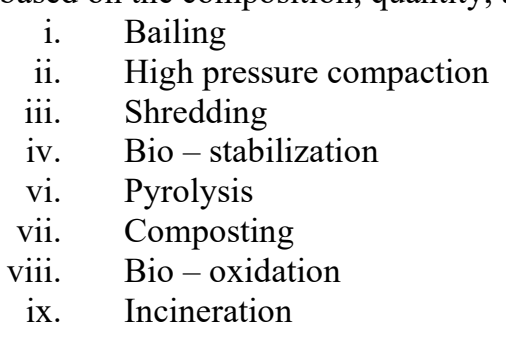

\subsubsection{Thermal treatment}

This refers to processes that involve the use of heat to treat waste. Listed below are descriptions of some commonly utilized thermal treatment processes.

\subsubsection{Incineration}

Incineration is the most common thermal treatment process. This is the combustion of waste in the presence of oxygen. After incineration, the wastes are converted to carbon dioxide, water vapour and ash. This method may be used as a means of recovering energy to be used in heating or the supply of electricity. In addition to supplying energy, incineration technologies have the advantage of reducing the volume of the waste, rendering it harmless, reducing transportation costs and reducing the production of the greenhouse gas such as methane.

\subsubsection{Pyrolysis and Gasification}

Pyrolysis and gasification are similar processes they both decompose organic waste by exposing it to high temperatures and low amounts of oxygen. Gasification uses a low oxygen environment while pyrolysis allows no oxygen. These techniques use heat and oxygen starved environment to convert biomass into other forms. A mixture of combustible and non-combustible gases as well as pyroligneous liquid is produced by these processes. All of these products have a high heat value and can be utilized. Gasification is advantageous since it allows for the incineration of waste with energy recovery and without the air pollution that is characteristic of other incineration methods

\subsubsection{Open burning}

Open burning is the burning of unwanted materials in a manner that causes smoke, and other emissions to be released directly into the air without passing through a chimney or stack. This includes the burning of outdoor piles, burning in a burn barrel and the use of incinerators which have no pollution control devices and as such release the gaseous by products directly into the atmosphere (Davidson, 2011). Open burning has been practiced by a number of urban centers because it reduces the volume of refuse received at the dump and therefore extends the life of their dumpsite. Garbage may be burnt because of the ease and convenience of the method or because of the cheapness of the method. In countries where house holders are required to pay for garbage disposal, burning of waste in the backyard allows the householder to avoid paying the costs associated with collecting, hauling and dumping the waste. Open burning has many negative effects on both human health and the environment. This uncontrolled burning of garbage releases many pollutants into the atmosphere. These include dioxins, particulate matter, polycyclic aromatic compounds, volatile organic compounds, carbon monoxide, hexachlorobenzene and ash. All of these chemicals pose serious risks to human health. The Dioxins are capable of producing a multitude of health problems; they can have adverse effects on reproduction, development, disrupt the hormonal systems or even cause cancer. The polycyclic aromatic compounds and the hexachlorobenzene are considered to be carcinogenic. The particulate matter can be harmful to persons with respiratory problems such as asthma or bronchitis and carbon monoxide can cause neurological symptoms. The harmful effects of open burning are also felt by the environment. This process releases acidic gases such as the halo-hydrides; it also may release the oxides of nitrogen and carbon. Nitrogen oxides contribute to acid rain, ozone depletion, smog and global warming. In addition to being a greenhouse gas carbon monoxide reacts with sunlight to produce ozone which can be harmful. The particulate matter creates smoke and haze which contribute to air pollution.

\subsubsection{Factors Determining the Treatment Option for Selection}

In solid waste treatment, one is faced with so many treatment options to choose from; the treatment options to be selected depend upon the following factors (Seadon, 2006):

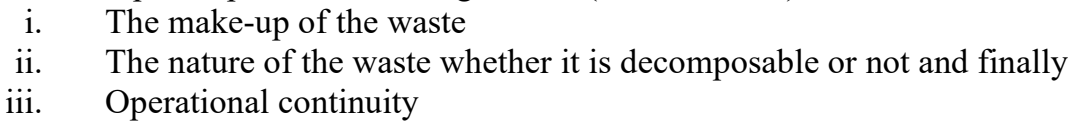

\subsection{Waste Disposal}

Three major method of disposal exist (Ogwueleka, 2009) and they are: 


\section{i. Open dumping \\ ii. Ocean dumping, and \\ iii. Burial (Land Filling)}

\subsubsection{Sanitary Landfills}

Sanitary landfills are sites where waste is isolated from the environment until it is safe. It is considered when it has completely degraded biologically, chemically and physically (Sener et al., 2010). Sanitary Landfills are designed to greatly reduce or eliminate the risks that waste disposal may pose to the public health and environmental quality. They are usually placed in areas where land features act as natural buffers between the landfill and the environment. For example, the area may be comprised of clay soil which is fairly impermeable due to its tightly packed particles, or the area may be characterized by a low water table and an absence of surface water bodies thus preventing the threat of water contamination. In addition to the strategic placement of the landfill other protective measures are incorporated into its design. The bottom and sides of landfills are lined with layers of clay or plastic to keep the liquid waste, known as leachate, from escaping into the soil. The leachate is collected and pumped to the surface for treatment. Boreholes or monitoring wells are dug in the vicinity of the landfill to monitor groundwater quality. This minimizes exposure to wind and rain. The daily waste is spread and compacted to reduce the volume; a cover is then applied to reduce odour and keep out pests. When the landfill has reached its capacity, it is capped with an impermeable seal which is typically composed of clay soil. Some sanitary landfills are used to recover energy. The natural anaerobic decomposition of the waste in the landfill produces landfill gases which include Carbon Dioxide, methane and traces of other gases. Methane can be used as an energy source to produce heat or electricity. Thus, some landfills are fitted with landfill gas collection (LFG) systems to capitalize on the methane being produced. The process of generating gas is very slow, for the energy recovery system to be successful there needs to be large volumes of wastes. These landfills present the least environmental and health risk and the records kept can be a good source of information for future use in waste management, however, the cost of establishing this sanitary landfill are high when compared to other land disposal method. Sanitary landfilling is the technique of disposing of refuse on land creating no nuisance or danger to public health or safety by applying the principles of engineering to restrict the refuse within a smallest practical volume and to cover it with a layer of earth at more frequent periods as may be required" (Olorunfemi, 2011). In many developing countries such as Nigeria, open or controlled dumping is largely used as the disposal method. The benefit of sanitary landfill over the other approaches or methods cannot be overemphasized because it is pollution-free and prevents water infiltration. Thus it eliminates any health or environmental risk that may result from solid waste disposal. Siting a sanitary or ordinary landfill requires an evaluation process in order to identify a potential suitable location. This location must comply with stipulated environmental regulations, and at the same time it must minimize economic and social costs (Olorunfemi, 2011).

\section{References}

1. Davidson, G., (2011), Waste management practices, literature review, 45 - 56

2. Davis, U.C (2008); The 4 R's of waste reduction, $34-56$

3. Egunjobi, T.O. (1983), "Problems of solid waste management in Nigerian urban centers", paper presented at the National Conference on Development and the Environment. Organized by NISER, University of Ibadan Nigeria

4. El-Haggar, S. M. (2007), Sustainable industrial design and waste management: Cradle-to-cradle for sustainable development, Oxford: Elsevier/Academic Press, 424

5. Kim, S. J. (2002); Korean waste management and eco-efficient symbiosis - a case study of Kwangmyong City, Clean Technologies and Environmental Policy, vol. 3(4), 12 - 23

6. Ogwueleka, T. Ch. (2009). Municipal solid waste characteristics and management in Nigeria. Department of Civil Engineering, University of Abuja, Nigeria. Iran. J. Environ. Health. Sci. Eng. 6(3): 173-180

7. Olorunfemi, F.B (2011) "Living with waste: major source of worries and concerns about landfill in Nigeria" Ethiopian J. Environ. Studies management, 2(2): 12-19

8. Peavy, H.S.; Rowe, D.R. and Tchobanoglous, G. (2008), Environmental Engineering, prentice - hall of India private limited, New Delhi, 56 - 78

9. Rao, P.V. (2004), Text book of Environmental Engineering, prentice - hall of India private limited, New Delhi, $86-88$

10. Seadon, J. K. (2006). Integrated waste management; looking beyond the solid waste horizon. Waste management Journal, vol.26(12), pp:1327-1336. doi: 10.1016/j.wasman.

11. Sener, S., Sener, E., Nas, B., Karagüzel, R., (2009); Combining AHP with GIS for landfill site selection: A case study in the Lake Beysehir, Waste Management (2010), doi.10.1016/j.wasman.2010.05.02441

12. Sincero, A.P. and Sincero, G.A. (2006), Environmental Engineering; a Design Approach, prentice - hall of India private limited, New Delhi, $67-120$.

13. Suttibak, S. and Nitivattananon, V. (2008); Resources, conservation and recycling assessment of factors 
influencing the performance of solid waste recycling programs. Conservation and Recycling, vol. 53, pp:4556. doi: 10.1016/j.resconrec.2008.09.004.

14. Tajuddin, I (2003); Solid Waste Management Strategy in Katsina Metropolis: A case study of Katsina Local Government Area. An unpublished undergraduate research project Department of Geography, Bayero University, Kano

15. Tudor, T., Robinson, G., Riley, M., Guilbert, S., and Barr, S. (2011); Challenges facing the sustainable consumption and waste management agendas: perspectives on UK households. Local Environment, vol.16(1), 51-66.

16. United State Environmental Protection Agency (USEPA) (1995); Decision-makers' guide to solid waste management, volume II. Washington, D.C. Retrieved from http://www.epa.gov/osw/nonhaz/municipal/dmg2/

17. United State Environmental Protection Agency (USEPA) (2010); Reduce, Reuse, Recycle. Wastes - Resource Conservation. Retrieved January 5, 2011, from http:/www.epa.gov/wastes/conserve/rrr/

18. United State Environmental Protection Agency (USEPA) (2012), Solid Waste and Emergency Response; EPA530-F-02-026a. 